\title{
¿E1 derecho está fundado en la acción colectiva? Comentario al artículo de Carlos Bernal
}

\author{
Damiano Canale* \\ (Traducción del inglés por Daniela Domeniconi)
}

Resumen: Este trabajo discute la obra de Bernal en la cual el autor analiza la tesis acerca de si el derecho está fundado en una práctica social. Para ello, propone una definición de "práctica social" como acción colectiva, inspirada en el debate contemporáneo que se da en el campo de la ontología social. Bernal considera que si el derecho se funda en una práctica social, esta práctica debe tener las características de la tesis de la práctica social. Puesto que la descripción del derecho dada por "los clásicos" Austin y Hart no da cuenta de tales características, estas descripciones son defectuosas y deberían ser modificadas. La teoría del derecho como un plan de Shapiro en este punto se encontraría mejor equipada para dar respuestas. Mostraré que Austin, Hart y Shapiro ponen en cuestión la tesis de la práctica social de Bernal, debido a que los tres autores brindan algunos argumentos en sentido contrario al pretendido por Bernal: la práctica que da fundamento al derecho (si la hay) no posee necesariamente esas características.

Palabras clave: práctica social, acción colectiva, ontología social.

Abstract: This paper discusses Bernal's work in which he analyzes the thesis about whether or not the Law is founded on a social practice. To this purpose, Bernal puts forward a definition of "social practice" as joint action inspired by the contemporary debate in the field of social ontology. Bernal affirms that, if law is founded on a social practice, this practice shall have the characteristics of the Social Practice Thesis. Since the pictures of law provided by Austin and Hart do not account

* Università Bocconi, (Milán, Italia), damiano.canale@unibocconi.it 


\section{Damiano Canale}

for such characteristics, these pictures are defective and should be amended. Shapiro's planning theory of law is much better equipped in this respect. I will show that Austin, Hart and Shapiro call into question Bernal's Social Practice Thesis, due to the fact that the authors provide some arguments to the contrary: the practice at the foundation of law (if any) does not necessarily have these characteristics.

Key words: social practice, joint action, social ontology.

\section{Introducción}

En la obra Austin, Hart y Shapiro: Tres variaciones alrededor del derecho como una entidad fundada en una práctica social, Carlos Bernal utiliza algunas herramientas conceptuales desarrolladas por la ontología social para analizar una de las tesis centrales en la teoría del derecho contemporánea: la idea de que el derecho está fundado en una práctica social.

A tal fin, Bernal propone una definición de "práctica social" como acción colectiva (o actividad conjunta) inspirada en el debate contemporáneo que se da en el campo de la ontología social. Así, él intenta determinar si las concepciones acerca de la práctica social en las que Austin, Hart y Shapiro, respectivamente, basaron sus teorías satisfacen las condiciones descriptas por esta definición. De este modo, afirma Bernal, el análisis es capaz de "iluminar nuevos aspectos de las teorías de Austin y Hart", y de "aclarar algunos aspectos básicos de la "teoría del derecho como un plan" de Shapiro" .

Desde la mirada de Bernal, la teoría de la práctica social sostiene que el derecho consiste en:

un conjunto recurrente de acciones intencionales colectivas llevadas a cabo de forma mancomunada por un cierto número de agentes individuales apropiados, que actúan como un todo, de acuerdo con, y en razón de, algunas intenciones comunes

1 Bernal Pulido, C., "Austin, Hart, y Shapiro. Tres variaciones alrededor del derecho como una entidad fundada en una práctica social", Discusiones, XIV, 2014, págs. 21-72. 
¿El derecho está fundado en la acción colectiva?

apropiadas [we-intentions $]^{2}$ y que comparten un conocimiento común necesario acerca de la acción y de las intenciones comunes de sus miembros para llevar a cabo tal acción como un grupo ${ }^{3}$.

Basándose en esta definición, el argumento de Bernal continúa del siguiente modo: si el derecho se funda en una práctica social, esta práctica debe tener las características mencionadas arriba [Social Practice Thesis]. Puesto que la descripción del derecho dada por Austin y Hart no da cuenta de tales características, estas descripciones son defectuosas y deberían ser modificadas. La teoría del derecho como un plan de Shapiro en este punto se encuentra mejor equipada: en efecto, satisface - con algunas precisiones - la tesis de la práctica social, y por ello aporta un marco bastante apropiado para una comprensión socio-ontológica del derecho.

La estrategia adoptada por Bernal en este artículo tiene al menos dos ventajas importantes. En primer lugar, muestra qué respuestas podría aportar la socio-ontología (o, mejor dicho, una cierta explicación de las entidades que pertenecen al ámbito de la realidad social)

2 [N. del T.: El término técnico we-intentions será traducido a lo largo del texto como "intenciones comunes".]

3 Ibíd. Esta definición describe la práctica que fundamenta al derecho como caracterizada por un conjunto de actitudes intencionales distintivas de los participantes involucrados en dicha práctica. Dichas actitudes incluyen (1) intenciones comunes subjetivas (un participante de la práctica hace $\mathrm{X}$ porque pretende que todos los participantes hagan $\mathrm{X}$ ) y conocimiento común (un participante de la práctica sabe que los otros participantes hacen X y que ellos pretenden que todos los participantes hagan igualmente $\mathrm{X}$, ella sabe que ellos saben que hace $\mathrm{X}$ y que ellos pretenden que todos los participantes hagan $X$, ella sabe que ellos saben que ellos saben que hacen X y que ellos pretenden que todos los participantes hagan X, y así ad infinitum). Bernal afirma que esta definición es neutral puesto que solo marca algunos supuestos comunes de la ontología social contemporánea. Esto es claramente cierto en lo que respecta a las intenciones comunes. El requerimiento de conocimiento común es mucho más controvertido y, además, es característico de la explicación de Bratman (y Shapiro) sobre la agencia compartida - shared agency - Ver Bratman, M., Faces of Intention, Cambridge, Cambridge UP, 1999, pág. 102. 


\section{Damiano Canale}

a cierto tipo de preguntas clásicas de la teoría del derecho, tales como “¿qué es el derecho?”, “ipor qué el derecho es normativo?”, “iqué distingue la práctica jurídica de otros tipos de prácticas sociales?", entre otras. En segundo lugar, conecta estas respuestas con la tradición de la teoría del derecho analítica: la lectura que hace la socio-ontología de las entidades jurídicas es presentada como un avance dentro de una tradición de pensamiento consolidada, en lugar de ser presentada como un marco teórico exótico que rechaza toda contribución de esta tradición para la comprensión del derecho.

Sin embargo, la estrategia de Bernal posee también algunos inconvenientes. El primero está relacionado con la estructura lógica del razonamiento de Bernal. Si la explicación $\mathrm{E}_{1}$ del hecho $\mathrm{F}$ no se corresponde con la explicación $\mathrm{E}_{2}$ de $\mathrm{F}$-en el sentido de que la anterior explicación no es consistente con la posterior, o no satisface los requerimientos indicados por ella- bien podría ser el caso que $\mathrm{E}_{1}$ sea inadecuada o falsa, mientras $\mathrm{E}_{2}$ sea, de hecho, informativa y verdadera. Pero podría ser el caso completamente opuesto, o incluso ambas explicaciones podrían ser defectuosas. En otras palabras, el hecho de que ciertas explicaciones del derecho no encuadren con la tesis de la práctica social no prueba que esta explicación sea inadecuada, ni que la tesis de la práctica social sea verdadera. Además, la estrategia de Bernal no permite que la tesis de la práctica social sea examinada, por lo que no provee ningún argumento genuino a favor de ella.

El segundo problema está relacionado con la disputa de Bernal con Austin y Hart. Me parece que hay al menos dos formas de leer un "clásico" de la teoría del derecho. Alguien bien podría leer los textos de Austin y Hart en búsqueda de una respuesta a una pregunta teórica acerca de la cual los filósofos del derecho contemporáneos sigan preocupados en la actualidad, incluso cuando esas preguntas hubieran sido inconcebibles para aquellos autores. Haciendo eso, nuestra lectura "renueva" el pensamiento de un autor, de tal modo que el autor puede ser reconocido por la categórica importancia de su teoría, o ser censurado por obsoleto. En lo particular, encuentro este tipo de lecturas filosóficamente sospechosas. Proyectan en un texto escrito en el pasado el marco conceptual del lector actual; de modo 
¿El derecho está fundado en la acción colectiva?

que una perspectiva filosófica se considera valiosa y relevante solo si concuerda con ese marco conceptual. Además, este tipo de lectura corre el riesgo de usar un texto filosófico para confirmar o desechar supuestos cuyo autor nunca expuso, o analizar problemas que el texto no aborda. Cuando esto sucede, hacer referencia a un "clásico" tal como Austin y Hart toma la forma de un argumento de autoridad, cuya conclusión podría ser falaz.

Se puede adoptar otro tipo de lectura de los "clásicos". E1 lector podría considerar los problemas filosóficos que el autor buscó resolver, el marco teórico utilizado para ello, y su marco contextual. El lector podría, entonces, evaluar - desde un punto de vista interno e imparcial - si cierta afirmación filosófica es sólida, coherente, perspicaz o incluso esclarecedora con relación al problema en cuestión. El lector puede, en otras palabras, evaluar y criticar un texto filosófico en sus propios términos. Esto reduce el riesgo de una "sobreinterpretación" y puede obligar al lector a reconsiderar sus propios supuestos a través de los métodos de la indagación, los conceptos, las distinciones o cuestiones de hecho que no haya tenido en cuenta previamente.

En la primera parte de su ensayo, Bernal parece elegir el primer modo de leer a los clásicos. Su lectura crítica de Austin y Hart se encuentra inspirada en el debate contemporáneo que se da en el campo de la ontología social y tiende no solo a apoyar la teoría del derecho como un plan de Shapiro, sino también a clarificarla y defenderla de algunas objeciones, en la segunda parte de su ensayo.

En este artículo seguiré el segundo tipo posible de lectura y lo extenderé a la interpretación de la obra Legality, de Shapiro, aunque el libro de Shapiro no sea (aún) un "clásico" para la teoría del derecho. En particular, mostraré que Austin, Hart y Shapiro ponen en cuestión la tesis de la práctica social de Bernal, i. e., la idea de que el derecho está fundado en un conjunto de acciones intencionales colectivas recurrentes, realizadas por agentes, actuando como un grupo, sobre la base de intenciones comunes y compartiendo un conocimiento común. En mi opinión, Austin, Hart y Shapiro brindan algunos argumentos en sentido contrario: la práctica que da fundamento al derecho (si la hay) no posee necesariamente esas características. 


\section{Damiano Canale}

Sosteniendo mi postura, no pretendo debilitar el valioso intento de Bernal de poner la ontología social en diálogo con la teoría del derecho, puesto que ese diálogo podría ser de gran importancia para esta última. Me interesa, más bien, destacar algunas características de las prácticas jurídicas que la tesis de la práctica social no tiene en cuenta. De hecho, me parece que las entidades jurídicas tienen rasgos que distinguen al derecho de otros fenómenos sociales tales como usar dinero, frecuentar un club de golf, limpiar la casa junto a alguien, o conducir del lado derecho de la calle. Prestar atención a estas similitudes no solo es una condición fundamental para lograr una explicación satisfactoria de las entidades jurídicas, sino que podría también mejorar la comprensión ontológica de la realidad social en general.

\section{Austin}

Siguiendo la tradición que data desde Thomas Hobbes, Austin sostiene que el derecho es un instrumento para ejercer el poder político. El derecho es un conjunto de órdenes respaldadas por amenazas de sanciones emitidas por el soberano con el fin de guiar la conducta de los destinatarios del derecho. El soberano, a su vez, es simplemente identificado como el hombre o el órgano que es generalmente obedecido y que no obedece a nadie ${ }^{4}$.

Desde la óptica de Bernal, la teoría del derecho como mandato de Austin puede ser vista como una versión de la tesis de la práctica social. Esto sería así puesto que la noción de Austin de "hábito de obediencia" puede ser equiparada a la noción de "acción intencional colectiva recurrente", lo cual nos permitiría analizar la anterior. Cuando obedecen al derecho, los miembros de una cierta sociedad

4 "Las nociones de soberanía y de sociedad políticamente independiente pueden ser expresadas brevemente así - Si un ser humano superior determinado, sin un hábito de obediencia a otro superior, recibe una habitual obediencia por parte de la mayoría en una sociedad dada, eso determina que el superior sea soberano en esa sociedad, y que la sociedad (incluyendo al superior) sea una sociedad política e independiente". Austin, J., The Province of Jurisprudence Determined, Cambridge, W. R. Rumble, 1995, pág. 166. 
actúan juntos: su actividad es una actividad social que depende de las órdenes emanadas del soberano, quien de este modo participa en la práctica. Además, visto que la obediencia general está motivada por la amenaza de sanciones, los destinatarios del derecho obedecen los mandatos jurídicos basándose en sus creencias, deseos e intenciones. El hábito general de obediencia es, entonces, una actividad colectiva intencional, ejecutada por el soberano y la mayoría de la población actuando conjuntamente como un grupo; una actividad que explica la naturaleza del derecho y su normatividad, i. e. el hecho de que las normas jurídicas sean guías para la acción [action-guiding].

Según Bernal, la versión austiniana de la tesis de la práctica social sería, sin embargo, defectuosa. Y lo sería por dos razones. En primer lugar, no es capaz de explicar la socialidad. Un hábito general de obediencia no es necesariamente una acción intencional colectiva. Podría suceder que cada miembro de una comunidad jurídica se atenga al derecho por un hábito independiente, motivado por intenciones individuales [I-intentions $]^{5}$ que inintencionadamente convergen con el hábito de los otros. Asimismo, el hábito de obediencia no requiere acciones comunes ni coordinación social. Cada miembro puede comportarse como un agente independiente y esto no afectaría la existencia de la soberanía ni del derecho. En segundo lugar, la versión austiniana de la tesis de la práctica social no da cuenta de la normatividad. No es capaz de reflejar algunos aspectos esenciales del derecho, en particular, el hecho de que algunos agentes consideran al derecho como una razón para la acción, de modo tal que toda desviación del hábito común es criticada y esta crítica se considera generalmente justificada, como advierte Hart. Así, la teoría del derecho como mandato no explica por qué las normas jurídicas generan obligaciones genuinas y por qué pueden ser autoritativas. Según Bernal, "Estas consideraciones conducen a la conclusión de que la teoría del derecho

5 [N. del T.: El término técnico I-intentions será traducido a lo largo del texto como "intenciones individuales".] 
de Austin no puede explicar el derecho como una práctica social en el sentido de una práctica colectiva ni en el de una práctica normativa"6.

Encuentro acertada la conclusión de Bernal. Si uno asume que el derecho se funda en una práctica social con las características descriptas por la tesis de la práctica social, entonces la teoría del mandato no provee una explicación convincente acerca de por qué el derecho obliga. Pero, a mi modo de ver, la premisa de Bernal es falsa. La noción de Austin de "hábito de obediencia" no puede ser equiparada a la noción de "acción intencional colectiva recurrente" sin perder su pretendido significado y su importancia teórica. De esto se sigue que la crítica de Bernal no logra su objetivo. La teoría del derecho como mandatos no es una versión de la tesis de la práctica social, sino que más bien arroja algunas dudas en cuanto a la idea de que el derecho se base en una acción colectiva intencional. ¿Por qué razones?

La noción de acción intencional colectiva fue primero presentada para dar cuenta de entidades sociales cuya existencia depende de lo que la gente realice en conjunto. La representación de Bernal de una acción colectiva, en particular, recurre a la intencionalidad colectiva (intenciones comunes subjetivas), que presentan la realidad social como un resultado - bajo ciertas circunstancias - de la cooperación social para un fin común o para diferentes fines subjetivos que se combinan entre sí. Por el contrario, la noción del derecho que tiene Austin es esencialmente no cooperativa. Se basa en la relación vertical entre el soberano y el resto de los miembros de una sociedad política, y en el dominio del primero por sobre los segundos. En palabras de Austin, "a ese superior determinado (el soberano), es que los otros miembros de la sociedad están sujetos: o de ese superior determinado es que los otros miembros de la sociedad son dependientes" ". La condición de sujeción se encuentra en los fundamentos del derecho, puesto que determina el contenido de términos tales como "ley", "orden", "deber", "responsabilidad", "derechos", "obligación", etc. ${ }^{8}$ Además,

${ }^{6}$ Bernal Pulido, C., op. cit., pág. 32.

7 Austin, J., op. cit., pág. 166.

8 "Estar expuesto a un daño proveniente de ti en caso de que yo no cumpliera tu deseo, implica que estoy sujeto u obligado por tu mandato, o que estoy 
¿E1 derecho está fundado en la acción colectiva?

la condición de sujeción es constitutiva de una sociedad política: en una sociedad política, las intenciones dirigidas de las normas son formalmente reemplazadas por aquellas del soberano a través de mandatos jurídicos, y solo cuando este reemplazo tiene lugar surge una sociedad política. Las sociedades políticas no son grupos sociales en un sentido naturalista: ellas no son el resultado de lo que la gente hace en conjunto. Son, más bien, artefactos sociales. Siguiendo a Hobbes, Austin define las sociedades políticas (comunidades humanas reguladas por el derecho) en oposición a las sociedades naturales tales como la familia, la iglesia, las universidades, etc. Una sociedad natural está compuesta por personas "que están conectadas por el trato mutuo" y que cooperan para alcanzar objetivos comunes ${ }^{9}$. Esto implica, en la perspectiva de Austin, que nadie vive en un estado de sujeción en las sociedades naturales. Esto no significa que el soberano, y quien se encuentre sujeto a él, no puedan llevar a cabo acciones colectivas o cooperar en miras a un fin común. La idea de Austin es que no es condición necesaria para la existencia del derecho, ni un aspecto de lo que el derecho en verdad es; sino que es más bien una cuestión de moral positiva que influye en la felicidad individual y el bienestar común. Si eso es cierto, ¿cuál sería entonces el papel que juega el hábito general de obediencia en el marco teórico de Austin?

Yo creo que el hábito general de obediencia, en este contexto, actúa como una suerte de contrato social a posteriori. Aunque Austin toma prestada principalmente de Hobbes su teoría política de gobierno, no afirma que la soberanía esté basada en un acuerdo ficticio entre individuos que transfieren sus derechos naturales a un órgano común. E1 punto de vista de Hobbes no puede ser defendido porque no cumple con los requerimientos del empirismo y no es necesariamente consistente con el principio de utilidad. La existencia de soberanía y de un gobierno político debe ser derivada de "una percepción por parte de

bajo el deber de obedecerlo [...]. Mandato y deber son, por lo tanto, términos correlativos: su significado denota que cada uno implica o supone al otro". Ibíd, pág. 22.

$9 \quad$ Ibíd., pág. 170. 
la mayoría de la población de su obvia y gran conveniencia" ${ }^{10}$. En otras palabras, si la mayoría de la población generalmente obedece un conjunto de órdenes emitidas por una persona que no tiene el hábito de obedecer a nadie más, luego esa persona es el soberano y lo que el soberano manda es el derecho: el acuerdo social implícito en el fundamento del derecho puede ser observado a posteriori, solo si prestamos atención al consentimiento social. Además, uno podría decir que la noción de hábito general de obediencia no forma parte del concepto de derecho: forma parte, más bien, del concepto de sociedad política. Si la obediencia general hacia el soberano se rompe, el derecho no desaparece necesariamente ${ }^{11}$. Parafraseando las palabras de Thomas Hobbes, Austin sostiene que "el legislador es aquel (no por cuya autoridad el derecho fue creado, sino aquel) por cuya autoridad el derecho sigue siendo derecho"12. Un mandato emitido por una autoridad que deja de ser obedecida por la mayoría de la población sigue siendo un mandato jurídico cuando otra autoridad lo hace cumplir. Cuando esto sucede, podemos observar un cambio en la composición de la sociedad política y no en el contenido de la ley ${ }^{13}$.

Sobre la base de dichas consideraciones, uno podría sostener que la teoría del derecho como mandato no puede entenderse como una versión de la tesis de la práctica social, debido a que la mayoría de la población y el soberano no actúan como grupo en un sentido socio-ontológico. Además, la imagen del derecho que presenta Austin excluye categóricamente la posibilidad de que las acciones intencionales colectivas formen parte de lo que el derecho en verdad es; sino

10 Ibid., pág. 230.

${ }^{11}$ Ibíd., págs. 282-283.

12 Ibíd., pág. 282.

${ }^{13}$ Esto puede ser visto como una respuesta implícita de Austin a la objeción de Hart según la cual la teoría del derecho como mandato no sería capaz de explicar la transición legal de un soberano al otro (ver Hart, H. L. A., The Concept of Law, Oxford, Clarendon Press, cap. 4). Uno podría argüir que la transición legal de Rex I a Rex II ocurre cuando las órdenes emitidas por Rex I siguen siendo generalmente obedecidas incluso si ahora es Rex II quien las ejecuta. 
¿El derecho está fundado en la acción colectiva?

que son más bien el resultado de un aspecto de la psicología humana que se encuentra conectado a la moral positiva.

Todo esto tiene un impacto significativo en el problema de la normatividad. Ahora bien, es definitivamente cierto que Austin no brinda una explicación muy confiable acerca de varios aspectos del derecho, como bien hubo de notar Hart. En particular, Austin no logra aportar una teoría convincente acerca de las normas que confieren potestades y del derecho constitucional en general. Además, él hace caso omiso de la naturaleza constitutiva de las normas jurídicas, i. e., el hecho de que las normas jurídicas sean aptas para constituir actividades e instituciones que no existirían si no fuese por ellas. Si este u otros aspectos del derecho no son tenidos en cuenta, o son sencillamente simplificados por Austin, en mi opinión, no puede actuarse del mismo modo al analizar la normatividad del derecho. Austin nos brinda una explicación psicológica acerca de por qué las normas son guías para la acción, y conecta esta explicación con el hábito general de obediencia. En la sexta conferencia de The Province of Jurisprudence Determined, Austin sostiene que la obediencia habitual al soberano se debe a tres factores principales: primero, "es en parte una consecuencia de la costumbre: ellos (i. e. la mayoría de la población) en parte obedecen al gobierno presente o establecido, porque ellos - y quizás sus antecesores - se han encontrado siempre en hábito de obedecerlo"; segundo, "es en parte consecuencia de los prejuicios" a favor de cierto tipo de gobierno o de las personas involucradas en él, y, finalmente, "en parte procede de una razón fundada en el principio de utilidad", i.e. la preferencia de un gobierno político por sobre la anarquía ${ }^{14}$.

De este modo, vemos que Austin no afirma que la obediencia general sea ocasionada por la amenaza de sanción. La sanción es simplemente una parte de la definición de norma jurídica, una definición que permite distinguir las normas jurídicas de otro tipo de normas sociales. En otras palabras, para Austin es conceptualmente verdadero que el derecho es un conjunto de órdenes respaldadas por la amenaza de una sanción. Por el contrario, el hábito de obediencia

${ }^{14}$ Ibíd., págs. 244-246. 


\section{Damiano Canale}

es un fenómeno empírico: puede ser verdadero o falso que la mayoría de la población generalmente respete el derecho. En este sentido, Austin reduce la normatividad del derecho a un hecho empírico: el hecho de que cuando el derecho existe, sus destinatarios se sienten, generalmente, obligados a obedecerlo. Y este sentimiento puede ser causalmente explicado por algunos hechos psicológicos relacionados con el principio de utilidad ${ }^{15}$.

Ahora bien, Hart sostuvo que una explicación como esa es insatisfactoria. El argumento principal de Hart es que la teoría de Austin acerca del hábito de obediencia no tiene en cuenta la distinción entre el comportamiento habitual y el seguimiento de reglas [rule-following]. El hábito de obediencia es simplemente una regularidad de conducta, mientras que seguir una regla implica tomar las normas jurídicas como razones para hacer aquello que el derecho manda y como razones para criticar a aquellos que se aparten de las normas ${ }^{16}$.

Bernal mantiene la objeción de Hart, como generalmente hace la teoría del derecho contemporánea, y la utiliza para apoyar la tesis de la práctica social. Pero ¿es justa la objeción de Hart? Uno podría sostener que no. En primer lugar, Austin no reduce la normatividad del derecho a la amenaza de sanción. El hecho de que las normas sean generalmente guías para la acción depende de un complejo conjunto de hechos psicológicos, del tipo de los que investiga la filosofía moral. En segundo lugar, esta explicación sigue siendo compatible con la idea de la existencia de reglas como razones para la acción. Hechos tales como que cierta autoridad haya sido obedecida en el pasado, la preferencia por una cierta forma de gobierno político, o la preferencia por un sistema de gobierno en lugar de la anarquía, pueden ser entendidos como razones que condicionan la deliberación práctica de los destinatarios del derecho y explican por qué algunos miembros de la

15 Por supuesto que la explicación psicológica de Austin acerca del hábito de obediencia podría parecer algo ingenua hoy en día. De todos modos, Austin muestra que la normatividad del derecho puede ser vista por la teoría del derecho como una cuestión de hecho que se encuentra abierta a la investigación científica. Sobre ello trata el último apartado de este artículo.

${ }^{16}$ Hart, H. L. A., op. cit., pág. 55. 
¿El derecho está fundado en la acción colectiva?

comunidad ven al derecho como un conjunto de reglas que regula adecuadamente las conductas. Para Austin esas razones son simplemente una parte de la explicación psicológica del comportamiento individual, que está fuera del ámbito de la teoría del derecho empírica. Si alguien entiende estas razones como parte de la explicación filosófica del derecho, entonces confunde la teoría del derecho con la teoría moral o la psicología.

En suma, me parece que Austin no encuentra el fundamento del derecho en una práctica social, ni podría haber concebido jamás la posibilidad de que el derecho dependa de una acción intencional colectiva. Austin, en verdad, remarca algunas características del derecho que la tesis de la práctica social parece pasar por alto: la idea de que la normatividad del derecho puede ser entendida como una cuestión de consentimiento y eficacia jurídica; el hecho de que las organizaciones jurídicas normalmente incluyan relaciones verticales entre quien ejerce el poder político o privado y sus subordinados; y el hecho de que la coerción juegue un rol importante en las organizaciones jurídicas como un incentivo para acatar el derecho ${ }^{17}$. Incluso cuando alguien da por sentado que la coerción no es una condición necesaria del derecho - como Hart, Shapiro, Bernal y muchos otros hacen- es difícil negar que la aplicación de la ley y la coerción sean aspectos fundamentales de lo que se entiende por derecho hoy en día, un aspecto que es digno de considerar desde un punto de vista teórico ${ }^{18}$. Parece que una noción ontológica de las entidades jurídicas debe tomar en consideración dichas características y explicarlas. En

17 "Una de las principales funciones del derecho, plasmada en una amplia gama de disposiciones jurídicas, es resolver este tipo de problemas obligando a los individuos a olvidar sus estímulos iniciales de abandonar el comportamiento cooperativo, o a actuar en contra de sus propios intereses a largo plazo. Amenazando con sanciones por incumplimiento, el derecho es capaz de prestar un servicio para las partes involucradas: les permite comportarse cooperativamente, generalmente en beneficio de los agentes, a pesar de su incentivo racional de hacer lo contrario". Marmor, A., Philosophy of Law, Princeton, Princeton University Press, pág. 43.

${ }^{18}$ Ver Schauer, F., "Was Austin Right After All? On the Role of Sanctions in a Theory of Law", Ratio Juris, 23, 2010, págs. 1-21. 


\section{Damiano Canale}

este sentido, las afirmaciones de Austin son un reto para la tesis de la práctica social, aunque la teoría del mandato falle en el intento de proveer una explicación satisfactoria de distintos aspectos del derecho.

\section{Hart}

Hart describe al derecho como una práctica social que consiste en la aceptación de una regla social - la regla de reconocimiento- por parte de los jueces y otros funcionarios de la justicia. Según Hart, una regla social existe cuando estos tres tipos de comportamiento tienen lugar: (a) la mayoría de los miembros de un grupo social se conforman regularmente al contenido de la regla; (b) si se les requiere que justifiquen lo que hacen regularmente, la mayoría de los miembros del grupo afirma que está siguiendo una regla, que es vista por ellos como una razón para actuar; (c) los miembros del grupo social apelan a la regla para ejercer presión hacia los otros miembros y para apoyar la crítica hacia quienes se desvíen de la regla. La segunda y la tercera condición de las reglas sociales muestra lo que Hart llama "la aceptación de una regla": "(la aceptación) consiste en la firme disposición de los individuos a considerar dichos patrones de conducta como pautas o criterios de conducta y como standards críticos que podrían legitimar demandas y otras formas de presión" ${ }^{19}$. Bernal se pregunta si la aceptación puede ser vista como una práctica social cuyas características sean las descriptas por la tesis de la práctica social. La aceptación jurídica, ¿depende de un conjunto de acciones intencionales colectivas realizadas por agentes, actuando conjuntamente como grupo, sobre la base de intenciones comunes y compartiendo un conocimiento común?

Bernal resalta que la aceptación de la regla puede ser explicada de dos modos diferentes. Un modo es brindar una lectura distributiva, de acuerdo con la cual la disposición de los miembros del grupo está constituida por intenciones individuales, que pueden ser diferentes unas de otras, aunque convergentemente motiven el mismo comportamiento. La aceptación de la regla, entonces, admite una interpretación 
colectivista: la disposición de los agentes está formada por intenciones comunes que los llevan a actuar como un grupo. Si la tesis de la práctica social es verdadera, la primera lectura no puede explicar la normatividad jurídica porque las intenciones individuales no son suficientes para la construcción de la realidad jurídica. Solo cuando las intenciones comunes entran en juego, y un número de personas calificadas actúan como grupo, los instrumentos jurídicos cobran vida.

Bernal sostiene correctamente que la explicación de Hart sobre la aceptación de las normas no está basada necesariamente en una interpretación colectivista. La imagen que presenta Hart de las reglas sociales es compatible con una descripción distributiva de las actitudes sociales; además, la práctica del derecho no incluye a la mayor parte de los destinatarios de las normas. Un sistema jurídico existe si la mayoría de los funcionarios aceptan la regla de reconocimiento que determina las condiciones de validez jurídica. Como resultado, la noción de Hart del derecho como práctica social es altamente problemática. En primer lugar, "no puede explicar por qué la práctica oficial da lugar a reglas que son jurídicamente vinculantes para toda la sociedad"20, en segundo lugar, Hart "Hart no explica por qué si las autoridades oficiales aceptan la regla de reconocimiento, quedan vinculadas por ella y por todas las demás reglas creadas de acuerdo con la regla de reconocimiento" 21 , en tercer lugar, "Hart puede explicar el hecho de que de la aceptación de la regla de reconocimiento por parte de las autoridades oficiales se siga que los ciudadanos también están vinculados por la regla de reconocimiento y todas las demás reglas generadas dentro del sistema jurídico, cuya fundamentación estribe en la regla de reconocimiento" 22 , finalmente, Hart no puede explicar la autoridad del derecho. Por un lado, la aceptación de la regla de reconocimiento por parte de los funcionarios es un elemento necesario de la práctica que da fundamento al derecho. Por otro lado, esta práctica no es capaz de explicar por qué los funcionarios son funcionarios. ¿De

${ }^{20}$ Bernal Pulido, C., op. cit., pág. 40.

${ }^{21}$ Ibíd, pág. 45.

${ }^{22}$ Ibid. 
dónde proviene su autoridad? Claramente no proviene de la regla de reconocimiento, puesto que esta es una norma que impone deberes y es generada por los mismos funcionarios. Por lo tanto, el argumento de Hart cae en el problema de la circularidad y no puede explicar por qué el derecho obliga.

Ahora bien, ¿se encuentra justificada la crítica de Bernal?

En El Concepto de Derecho de Hart, el término "aceptación" se refiere a diferentes actitudes intencionales que un observador está justificado en atribuir a ciertos individuos sobre la base de lo que esos individuos hacen o dicen. Entonces, esas actitudes son entendidas como hechos que pueden ser inferidos de lo que observamos en la realidad. En segundo lugar, estos hechos son hechos sociales: su explicación requiere que observemos cómo se relacionan las personas entre sí. A diferencia de Austin, que nos brinda una explicación psicológica del hábito de obediencia basado en actitudes individuales, Hart propone una explicación sociológica del cumplimiento de las reglas. El respeto hacia las reglas puede ser comprensible solo si consideramos las actitudes sociales que son distintivas de los participantes de una práctica social. Pero Bernal se pregunta ¿cómo puede una práctica social generar reglas?, y ¿por qué son estas reglas obligatorias (dan razones - reason-giving-)? A mi entender esta pregunta está mal formulada. Según Hart, una práctica social no genera reglas sociales. El concepto de regla social simplemente explica lo que una práctica social en verdad es: por qué los miembros de un grupo se comportan de cierta manera y qué acciones se necesitan para ser miembro del grupo, i.e., un participante de la práctica. Para decirlo de otro modo, hay una "relación interna" entre regla y práctica: la primera no puede ser explicada independientemente de la segunda, y viceversa ${ }^{23}$. Entonces, contrario a lo que Bernal sostiene en su artículo, Scott Shapiro está en lo correcto cuando afirma que las prácticas y las reglas pertenecen a dos dominios metafísicos distintos. Las prácticas sociales son conjuntos de actos con conexiones mutuas, mientras las reglas son entidades abstractas

${ }^{23}$ Baker G. P. y Hacker, P. M. S., Wittgenstein: Rules, Grammar and Necessity. London: Blackwell, 2009, pág. 135. 
¿El derecho está fundado en la acción colectiva?

que explican la existencia de una práctica social, hacen posible identificarla observando la realidad social, y son utilizadas para guiar y justificar el comportamiento individual. Ahora bien, ¿la aceptación de una regla social implica el compromiso de seguir la regla? En otras palabras, ¿debe un observador atribuir actitudes tales como creencias, deseos o intenciones a los participantes de una práctica social para identificar este tipo de práctica y las reglas que la gobiernan? Bernal explica que "es posible pensar en que los destinatarios del derecho aceptan las reglas sin siquiera pensar en que en ellos se ha formado la intención de obedecerlas" 24 . Hay reglas que aceptamos sin intención alguna, sobre la base de suposiciones o hábitos de los cuales no somos conscientes. Esta explicación, sin embargo, confunde las prácticas sociales guiadas por reglas con otras formas de comportamiento social. Cuando respetamos una regla inintencionadamente, no estamos siguiéndola en el sentido descripto por Hart. Estamos simplemente actuando de acuerdo con la regla, puesto que la regla en cuestión no nos brinda ninguna guía para nuestra acción. Haríamos lo que hacemos incluso si la regla no existiera en absoluto. Una persona haciendo $\phi$ cuenta como el seguimiento de una regla solo si la regla es parte de sus razones para hacer $\phi$. Por lo tanto, para que el comportamiento de una persona cuente como un caso de seguimiento de reglas, esta persona debe seguirla intencionalmente ${ }^{25}$. Sin la atribución de actitudes intencionales a los agentes, un observador no sería capaz de distinguir los hábitos sociales del comportamiento guiado por reglas. Si todo esto es cierto, el problema de la normatividad jurídica es formulado por Bernal de una manera que da lugar a la malinterpretación de la idea de Hart sobre la aceptación de la regla. Para Bernal y muchos otros, el problema de la normatividad es el problema de explicar por qué tenemos razones para obedecer al derecho. ¿De dónde provienen estas razones? Para Hart, por el contrario, el problema es el de explicar qué es para un grupo social tratar al derecho como proveedor de razones para comportarse de cierto modo, criticar a aquellos que se desvían,

${ }^{24}$ Bernal Pulido, C., op. cit., pág. 35.

${ }^{25}$ Baker G. P. y Hacker, P. M. S., op. cit. (nota 21), pág. 137. 
y tomar esa crítica como justificada. Como Kevin Toh correctamente señaló,

la (normatividad del derecho) no es un problema dirigido a los participantes de un sistema jurídico que están tratando de determinar qué consideraciones (si las hay) realmente justifican una conducta respetuosa del derecho. Es, en su lugar, un problema dirigido a los observadores de un sistema jurídico acerca de qué hechos garantizan la atribución de una práctica gobernada por el derecho a una comunidad ${ }^{26}$.

De ello se sigue que Hart no esté interesado en investigar por qué los funcionarios y los ciudadanos cumplen la ley, ni bajo qué condiciones las reglas de un sistema jurídico (incluyendo la regla de reconocimiento) son valiosas y deberían ser aceptadas. El cumplimiento de las leyes puede estar motivado por diferentes conjuntos de creencias, deseos e intenciones. Para la teoría del derecho, entendida como una forma de "sociología descriptiva", basta especificar bajo qué condiciones la conducta humana puede ser propiamente descripta como gobernada por el derecho. La misma consideración se aplica al rol de los ciudadanos en un sistema jurídico. Hemos visto que desde el punto de vista de Bernal, Hart falla en explicar por qué los ciudadanos se encuentran generalmente obligados por las reglas primarias y secundarias basándose en la aceptación de la regla de reconocimiento por parte de los funcionarios. Hart arguye, sin embargo, que los ciudadanos no necesitan compartir, aceptar o considerar como obligatoria ni la regla de reconocimiento ni las reglas primarias ${ }^{27}$. En sociedades

${ }^{26}$ Toh, K., "The Predication Thesis and a New Problem about Persistent Fundamental Legal Controversies", Utilitas, 22, 2010, pág. 333.

${ }^{27}$ Hart, H. L. A., op. cit., nota 11, pág. 112. De hecho, Hart no especifica claramente quienes son los individuos cuya práctica constituye la regla de reconocimiento. A veces se refiere a "la práctica de los tribunales, legislaturas, funcionarios y ciudadanos", algunas veces parece atribuirle una especial importancia a la práctica judicial. Véase Hart, H. L. A., op. cit., pp. 104-105. Desde un punto de vista conceptual, sin embargo, la regla de reconocimiento está dirigida solo a los funcionarios. Ver Raz, J., The Authority of Law. Essays on Law and Morality. Oxford: Clarendon Press, 1979, págs. 92-93. 
complejas como las nuestras — afirma Hart—la aceptación general de las reglas jurídicas por parte de la mayoría de la población no sería más que ficción; "un gran porcentaje de los ciudadanos comunes - quizás la mayoría - no tienen ninguna concepción general de la estructura jurídica o sus criterios de validación. El derecho que obedecen es algo que ellos conocen solamente como "el derecho" 28 . Los ciudadanos obedecen al derecho por una amplia variedad de razones diferentes, en la mayoría de los casos simplemente porque creen que "será mejor [para ellos] hacerlo"29. Pero Hart sostiene que indagar en las características y las fuentes de estas razones no es un asunto relevante para la teoría del derecho: "Siempre que las leyes, que son validadas por las pruebas de validez del sistema, sean obedecidas por la mayoría de la población, tendremos toda la evidencia que necesitamos" — junto con la aceptación de las reglas secundarias por parte de los funcionarios- "para establecer que cierto sistema jurídico existe" ${ }^{30}$. Tal como sucede en la teoría de Austin, una indagación acerca de las fuentes de las obligaciones jurídicas es una cuestión que le importa a la filosofía moral y la teoría política, que además se encuentran mejor equipadas para este propósito.

Finalmente, Bernal afirma que la teoría del derecho de Hart no es capaz de explicar por qué los funcionarios son funcionarios: si la regla de reconocimiento es la regla seguida por los jueces, ¿cómo pueden los jueces tener poder para tomar decisiones autoritativas gracias a esa misma regla? Ahora bien, me parece que esta objeción no es particularmente una amenaza para Hart. Dada la relación interna entre prácticas y reglas sociales, uno podría pensar que el rol de los jueces está constituido por la regla de reconocimiento que, de hecho, es considerada por Hart como una regla "definicional" 31 . Como Andrei Marmor bien señaló:

\footnotetext{
${ }^{28}$ Hart, H. L. A., op. cit., pág. 114.

${ }^{29} I b i ́ d$.

30 Ibíd.

${ }^{31}$ Ibíd, pág. 111.
} 


\section{Damiano Canale}

cuando tenemos un conjunto de reglas que constituye un cierto tipo de actividad [...], las reglas pueden constituir tanto el tipo de actividad en cuestión, como los roles particulares que las personas ocupan en la actividad. Y, por supuesto, las reglas son aquellas que efectivamente son seguidas por las personas involucradas en la actividad en cuestión ${ }^{32}$.

Para finalizar, es verdad que Hart no presupone que el derecho esté fundado en una práctica social con las características descriptas por la tesis de la práctica social. No obstante, esta no es una razón concluyente para desestimar la teoría práctica del derecho de Hart por defectuosa. Ciertamente, nada de esto significa que la teoría práctica de las reglas de Hart no pueda ser criticada en algunos aspectos. Por ejemplo, alguien podría notar que la concepción de Hart sobre las reglas sociales falla al no distinguir el comportamiento guiado por reglas de las acciones que se encuentran justificadas por razones que no son reglas ${ }^{33}$. O bien alguien podría argumentar que la teoría práctica "despoja a las reglas de su carácter normativo" debido a que las afirmaciones que dan prueba de la aceptación de las reglas pueden ser hechas por una persona que mire al derecho desde un punto de vista externo ${ }^{34}$. O alguien podría, también, argüir que la teoría práctica no da cuenta del desacuerdo jurídico: hay profundas y persistentes controversias acerca del último criterio de validación de las normas, de modo que un sistema jurídico no puede ser identi-

${ }^{32}$ Marmor, A., op. cit., pág. 56. Ver también: Coleman, J. L., The Practice of Principle. In Defence of a Pragmatist Approach to Legal Theory, Oxford, Oxford University Press, 2001, pág. 101.

${ }^{33}$ Ver Warnock, G. J., The Object of Morality, London, Methuen, 1971, págs. 45-46. Según Warnock, "una persona actúa en cumplimiento de una regla, por ello 'está' esa regla. [...] Si alguien supone que él mismo (o uno) debe actuar de tal o cual modo en cualquier caso que se presente, hay pues buenas razones para hacerlo. [...] De hecho, sostener que existen esas razones, y estar dispuesto a apelar a ellas, lleva a pensar que una regla parece implicar típicamente estas inclinaciones, sin prestar demasiada atención al caso particular". Ibíd, pág. 47.

${ }^{34}$ Raz, J., Practical Reason and Norms. Oxford: Oxford University Press, 1990 [1975], pág. 58. 
¿El derecho está fundado en la acción colectiva?

ficado observando un supuesto comportamiento convergente de los jueces" 35 . Estas y otras objeciones han estado en el centro de un vívido debate en el seno de la teoría del derecho que, ciertamente, excede este artículo. Teniendo en cuenta los argumentos esgrimidos en este artículo, sin embargo, me parece que la debilidad de la teoría práctica de Hart no depende del hecho de que Hart no identifique qué actitudes y motivaciones subjetivas hacen posible la existencia de la obligación jurídica. De hecho, los problemas mencionados desaparecen si uno pone en claro la estructura de la práctica jurídica, i. e. como se da en el caso de que los participantes involucrados en una práctica guiada por reglas jurídicas actúen de modo tal que puedan tener un efecto particular entre sí, un efecto que normalmente llamamos "tener una obligación jurídica de hacer esto-y-aquello". Esto no significa que indagar en las fuentes de la obligación jurídica no sea filosóficamente atractivo. Todo lo contrario. Pero una indagación de este tipo podría ser llevada adelante de mejor manera en la interacción entre la filosofía moral, la sociología y las ciencias cognitivas, dada la naturaleza interdisciplinaria del problema de la normatividad, que requiere una "división lingüística del trabajo" 36 entre las disciplinas. En efecto, encomendarle a la teoría del derecho este tipo de indagación corre con el riesgo de reducir la teoría del derecho a una rama de la teoría moral, o de fomentar una (incorrecta) vía a través de la cual el análisis de los conceptos jurídicos pueda ser fácilmente reemplazado por la investigación empírica ${ }^{37}$.

Si todo esto es cierto, la teoría práctica de Hart implícitamente plantea algunos problemas para la tesis de la práctica social, que vale la pena considerar. Primero, Hart subrepticiamente niega que una

${ }^{35}$ Dworkin, R., Law's Empire. Cambridge-London: Belknap Press of Harvard University Press, 1986, pág. 3 y ss.

${ }^{36}$ Cf. Putnam, H., "The Meaning of Meaning", en Putnam, H. (ed.), Mind, Language and Reality, Cambridge, Cambridge University Press, 1975, págs. 227-229.

${ }^{37} \mathrm{He}$ discutido este problema metodológico en Canale, D., "Consequences of Pragmatic Conceptualism. On the Methodology Problem in Jurisprudence", Ratio Juris, 22, 2009, págs. 171-186. 
explicación filosófica de la normatividad del derecho deba elucidar por qué las normas jurídicas obligan, en el sentido en que Bernal lo entiende. De hecho, los supuestos de Bernal afectan fuertemente las tareas y los métodos de la teoría del derecho contemporánea: si uno piensa que estos supuestos son correctos, entonces no necesitaríamos encontrar una metodología filosófica bastante diferente a la de Hart. Segundo, Hart muestra, convincentemente, que no es condición necesaria para la existencia de un sistema jurídico que los ciudadanos acepten las reglas jurídicas y actúen de modo conjunto para lograr objetivos comunes. En realidad, un sistema jurídico puede existir aunque esto no suceda y los destinatarios de las normas las cumplan inintencionadamente, o motivados por intenciones individuales subjetivas. En este sentido, Hart parece sugerir que las instituciones jurídicas son entidades sociales que difieren esencialmente de fenómenos tales como el dinero, las familias o los clubes de golf, si bien estas comparten algunas características en común con aquel fenómeno. Esta es una idea que también motiva la noción de Scott Shapiro acerca de la práctica jurídica, tema que consideraré en el próximo apartado.

\section{Shapiro}

En la última parte de su ensayo, Bernal ofrece una admirable, clara y detallada reconstrucción de la teoría del derecho como un plan de Shapiro, que parece considerar las actividades jurídicas como sensibles a los "avances [...] en el campo de la ontología social" 38 .

Bernal presenta la teoría de Shapiro del derecho como un plan compuesto por dos elementos fundamentales: una teoría de los planes y una teoría de la práctica jurídica como una actividad de planeamiento social. Como ha demostrado Michael Bratman, el planeamiento es una característica de la psicología humana a la que recurrimos en situaciones en que, para cumplir nuestros objetivos, nuestra conducta necesita algún tipo de guía y coordinación sostenida en el tiempo, lo que trae consigo compromisos de acciones futuras. La 
¿El derecho está fundado en la acción colectiva?

actitud de planificar, en particular, hace posible realizar estas actividades conjuntamente, $i$. e. ejecutar acciones colectivas para alcanzar metas comunes. Según la interpretación que hace Shapiro de la visión de Bratman, los planes se caracterizan por un número específico de características que Bernal enumera con exactitud: los planes son parciales y tienen una estructura compleja, son compuestos (tienen partes que son planes en sí mismas), pueden ser diseñados para otras personas, pueden regular actividades masivas, reducen los costos deliberativos, pueden compartirse, y, por último, generan obligaciones genuinas: cuando una persona establece un plan, está racionalmente obligada a llevarlo a cabo.

Estas características particulares le permiten a Shapiro entender las actividades jurídicas como actividades socialmente planeadas. Las normas jurídicas pueden ser entendidas como planes, o como entidades similares a los planes, que coordinan el comportamiento social y hacen posible el resolver dudas y desacuerdos sobre los aspectos morales que afectan la vida social. Además, el concepto de plan puede ser utilizado para explicar el carácter institucional de los sistemas jurídicos. Cuando los grupos involucrados en hacer y llevar adelante los planes jurídicos son muy grandes, se necesitan ciertas jerarquías entre todos aquellos cuyas actividades deben ser coordinadas. Esta división vertical del trabajo requiere planes para hacer planes, que determinan, entre otras cosas, quién se encuentra autorizado para hacer planes por otros y para hacer cumplir los planes sociales cuando estos no sean compartidos por todos. Los sistemas jurídicos entonces incluyen un "plan maestro" que tiene la misma función que la regla de reconocimiento de Hart: su propósito es "guiar, organizar y monitorear la actividad común de los funcionarios de la justicia"39. Pero ¿bajo qué condiciones existe un plan maestro? Como Bernal ha notado, Shapiro "está de acuerdo con Hart en que las reglas fundamentales de un sistema jurídico existen solo si las autoridades oficiales adoptan una actitud de aceptación frente a ellas." ${ }^{40}$. Shapiro, sin embargo, agrega

39 Shapiro, S., Legality, Cambridge, Harvard University Press, 2011, pág. 177.

${ }^{40}$ Bernal Pulido, C., op. cit., pág. 55. 


\section{Damiano Canale}

una restricción adicional: "dado que las reglas fundamentales son elementos de un plan compartido, ellas necesitan que las autoridades oficiales tengan una actitud más compleja hacia ellas que la del punto de vista interno de Hart" 41 . Aceptar un plan implica comportarse en consecuencia, y permitir a los otros que lo cumplan del modo en que lo requiere la racionalidad instrumental. A diferencia de la regla de reconocimiento de Hart, el plan maestro es intrínsecamente normativo y sus contenidos dependen de la actividad intencional compartida de los funcionarios.

Teniendo esto en cuenta, Bernal llega a la conclusión de que la teoría del derecho como un plan satisface los requisitos de la tesis de la práctica social. En primer lugar, las actividades planificadas son "conjuntos de acciones intencionales colectivas": compartir un plan es algo que los miembros del grupo hacen juntos. Por lo tanto, el concepto de Shapiro de compartir un plan no admite una lectura distributiva: "mediante el diseño y desarrollo de un plan, todos los miembros de un grupo cumplen intencionalmente con su parte, y solo por esta razón es que el plan logra ser diseñado y desarrollado" 42 . En segundo lugar, compartir un plan presupone un conocimiento común: uno no puede compartir un plan sin saber cuál es su contenido. Finalmente, compartir un plan implica que los miembros del grupo social tengan una actitud colectiva: la actitud de aceptar el plan. Obviamente, Shapiro no considera que las prácticas jurídicas sean una actividad única intencional y colectiva, sino que ve al derecho como un compuesto de distintas actividades colectivas intencionales llevadas a cabo por diferentes grupos sociales. Sin embargo, y como sucede también con la noción de Hart de la regla de reconocimiento, un sistema jurídico solo existe si los funcionarios aceptan el plan maestro, independientemente de lo que los otros hagan.

La reconstrucción de Bernal es clara y está bien articulada. Sin embargo, no pone el acento de modo suficiente en uno de los supuestos fundamentales de la teoría del derecho como un plan. 
¿El derecho está fundado en la acción colectiva?

Shapiro afirma que un aspecto fundamental del derecho es su carácter institucional: "la actividad jurídica es una actividad compartida en la que varios actores jurídicos involucrados cumplen ciertos roles en la misma actividad de planeamiento social: algunos participan haciendo los planes y algunos participan aplicándolos" 43 . Como consecuencia, "la normatividad del derecho es 'institucional' naturalmente, que es lo mismo que decir que las relaciones jurídicas pueden regir entre las personas independientemente de la intenciones particulares de esas personas" 44 . Las autoridades jurídicas necesitan no estar comprometidas en la actividad compartida de planeamiento social para hacer eso: "él, ella, o ellos deben encontrarse completamente alienados del proceso. A una autoridad jurídica se le requiere simplemente que acepte el plan maestro compartido del sistema"45. Pero ¿bajo qué condiciones los oficiales aceptan el plan maestro? La aceptación no depende de las actitudes individuales: simplemente requiere que quien adopte un plan lo lleve a cabo y permita que los otros participantes de la actividad compartida hagan su parte.

Consecuentemente, Shapiro da lugar para pensar al derecho como una tecnología impersonal y social que ayude a los destinatarios del derecho a lograr sus objetivos y resolver los conflictos sociales. Esto es posible debido a la peculiar estructura de los planes. Como he ya explicado en otro artículo ${ }^{46}$, el concepto de plan designa una función operativa para la guía de la conducta humana de carácter recursivo. Esto le permite a Shapiro explicar la naturaleza de los fenómenos sociales masivos, tales como el derecho, mediante su reconstrucción como un grupo de regularidades funcionales que son cada vez más complejas, pero que tienen idénticas propiedades funcionales. Si uno da esto por hecho, el rol reconocido por la tesis de la práctica social de Bernal a las actitudes intencionales, en la explicación de las actividades compartidas, puede ser sustituido por otros planes que

${ }^{43}$ Shapiro, S., op. cit., pág. 204.

${ }^{44}$ Ibíd., pág. 210 (énfasis agregado). Ibid., pág. 204.

${ }^{45}$ Ibíd., pág. 204.

${ }^{46}$ Ver Canale, D., "Looking for the Nature of Law: On Shapiro's Challenge", Law and Philosophy, 31, 2012. 
establezcan los procedimientos que los oficiales deben seguir al aplicar un plan o planificar para otros. En otras palabras, en una actividad compartida masiva, las intenciones comunes pueden ser sustituidas por procedimientos comunes [we-procedures ${ }^{47}$ ] expresados por planes o normas similares. Un plan maestro, como cualquier otro plan jurídico, puede ser una herramienta impersonal, cuyo contenido no depende necesariamente - una vez que ha sido promulgado - de las actitudes e intenciones subjetivas.

Esta idea tiene algún paralelismo con la noción de Max Weber sobre la autoridad jurídica basada meramente en bases racionales. Según Weber, en el caso de las autoridades jurídicas la obediencia se debe a reglas impersonales legalmente establecidas, que obligan a sus destinatarios en tanto esas reglas sean entendidas como "el derecho", i. e. en tanto hayan sido emitidas por aquel que tiene el rango de autoridad gracias a otras reglas jurídicas ${ }^{48}$. Weber sostiene, sin embargo, que los funcionarios "son personalmente libres y están sujetos a la autoridad solo en lo concerniente a sus obligaciones oficiales impersonales" 49 . Las actitudes y las disposiciones de los funcionarios simplemente no interesan para la existencia y la normatividad del derecho, que depende de la estructura racional de los modernos sistemas jurídicos. ¿Cuáles son las ventajas de la autoridad jurídica impersonal, por sobre las otras formas de autoridad? Por un lado — explica Weber-,

la experiencia tiende universalmente a demostrarnos que un tipo de organización administrativa puramente burocrática [...] es, desde un punto de vista exclusivamente técnico, capaz

${ }^{47}$ [N. del T.: El término técnico we-procedures será traducido a lo largo del texto como "procedimientos comunes".]

${ }^{48}$ Weber, M., Economy and Society. An Outline of Interpretive Sociology. BarkelyLos Angeles-London: G. Roth and C. Wittich, 1978, pág. 215.

${ }^{49} \mathrm{Ibíd}$., pág. 220 (énfasis añadido). Según Weber, este es el resultado de un proceso de especialización, institucionalización y burocratización de los regímenes jurídicos de la era moderna. Es de notar, sin embargo, que un sistema jurídico no ofrece sus fundamentos desde esta perspectiva: los regímenes jurídicos modernos tienen su origen en una expropiación del poder político basado en fundamentos racionales. 
¿El derecho está fundado en la acción colectiva?

de alcanzar el más alto grado de eficiencia; y en este sentido, formalmente, los medios más racionales de ejercer la autoridad sobre los seres humanos ${ }^{50}$.

Por otro lado, sin embargo, las reglas autoritativas impersonales pueden adquirir cualquier tipo de contenido. Como Shapiro asegura, un plan maestro "puede ser moralmente detestable". Puede ceder el control total de un planeamiento social a un ruin dictador o privilegiar los derechos de ciertos subgrupos sociales de una comunidad en detrimento de otros. El plan compartido podría no tener ningún respaldo por parte de la población en general; los gobernados podrían odiarlo completamente. No obstante, si los hechos sociales son regidos por los planes compartidos - si la mayoría de los funcionarios acepta un plan accesible y público diseñado para ellos - entonces el plan compartido existirá. Y los funcionarios pueden aceptar el plan maestro incluso si ellos no se comportan como un grupo actuando en base a las actitudes comunes [we-attitudes] ${ }^{51}$. Por consiguiente, Legality presenta al derecho como una tecnología social inquietante - como sugiere de algún modo el color oscuro elegido para la tapa del libro-, una tecnología que permite a las personas coordinar y controlar las actividades sociales masivas con el costo de (potenciales) injusticias o arbitrariedades por parte de los funcionarios.

De hecho, Bernal hace notar que desde el punto de vista de Shapiro las actividades jurídicas no son necesariamente actividades intencionales:

la normatividad del derecho es institucional. No depende de las intenciones de las autoridades oficiales sino de las autorizaciones que ellas reciben para crear normas jurídicas y de los planes que explican cómo deben utilizarse tales autorizaciones. Las intenciones son remplazadas por los procedimientos ${ }^{52}$.

${ }^{50}$ Ibíd., pág. 223.

${ }^{51}$ [N. del T.: El término técnico we-attitudes será traducido a lo largo del texto como "actitudes comunes".]

${ }^{52}$ Bernal Pulido, C., op. cit., pág. 59. 
No obstante, Bernal no extrae todas las posibles consecuencias de un supuesto como este.

En primer lugar, en Legality el concepto de plan compartido admite una interpretación distributiva. Por un lado, Shapiro afirma que un plan compartido existe "solo en el caso de que el plan haya sido diseñado pensando en el grupo, de modo que ellos puedan comprometerse en una actividad colectiva" 53. Por otro lado, sin embargo, "la teoría del derecho como un plan requiere que los funcionarios acepten las reglas jurídicas fundamentales, como condición de su existencia" ${ }^{44}$ y la condición de aceptación se da cuando los funcionarios llevan adelante el plan maestro independientemente de sus actitudes intencionales: la aceptación no necesariamente consiste en (o depende de) intenciones comunes. Alguien podría rebatir esto haciendo notar que Shapiro no descarta del todo la función de las actitudes comunes y de las intenciones en la agencia compartida masiva. "Por supuesto - afirma- la institucionalidad del derecho se funda, en última instancia, en intenciones. Las reglas son jurídicamente válidas porque fueron creadas conforme a una regla que la mayoría de los funcionarios efectivamente acepta" 55 . Sin embargo, las intenciones comunes deben caracterizar solo la actividad de quienes diseñan el plan maestro, es decir, de los creadores de la primera constitución. Una vez que el plan maestro ha quedado establecido, los funcionarios pueden desempeñar su función simplemente acudiendo a fundamentos procedimentales. Podríamos imaginar un sistema jurídico en el cual tanto los ciudadanos como los funcionarios estén completamente alienados, en el sentido de que actúen sin pensar en el grupo, pero sigan siendo capaces de cooperar y resolver conflictos morales mediante la herramienta del planeamiento.

Estas consideraciones muestran que la expresión "la práctica en que se funda el derecho" es ambigua. Puede referirse a la práctica social que da origen a un sistema jurídico. Según la teoría del derecho como un plan, el fundamento original de un sistema jurídico requiere

${ }^{53}$ Shapiro, S., op. cit., pág. 177.

${ }^{54}$ Ibíd., pág. 183.

$100 \quad{ }^{55}$ Ibíd., pág. 211. 
que los autores del plan maestro actúen pensando en el grupo: así como en el acuerdo constitucional moderno el plan maestro emerge en el nombre de "nosotros, el pueblo", i. e. en nombre de un grupo colectivo. En otras palabras, los autores deben determinar las reglas fundamentales del sistema jurídico sobre la base de intenciones comunes y conocimiento común para lograr sus objetivos. Pero la misma expresión podría designar lo que garantiza la existencia de un sistema jurídico en el tiempo. Una vez que un sistema jurídico ha sido establecido, y el plan maestro se encuentra asentado, la intencionalidad colectiva podría no caracterizar la actividad de los funcionarios. Ellos podrían ejercer funciones institucionales basándose en intenciones individuales en búsqueda de la satisfacción de sus necesidades e intereses particulares. Lo que importa, en verdad, es que los funcionarios lleven a cabo el plan que los otros han diseñado para ellos. En otras palabras, el que un funcionario haga $\phi$ motivado por intenciones individuales cuenta como llevar adelante un plan jurídico si el hacer $\phi$ es parte de un procedimiento individual, directa o indirectamente emitido en virtud del plan maestro.

Si esto es cierto, alguien podría preguntarse si una agencia colectiva masiva tal como el derecho puede seguir siendo vista como una forma de una actividad colectiva compartida. Además, alguien podría preguntarse si la teoría del derecho como un plan provee una explicación confiable acera de la normatividad del derecho.

Bruno Celano ha manifestado que los planes no pueden ser usados para un planeamiento social masivo. Ellos son "herramientas de auto administración" que no son aptas para guiar y coordinar el comportamiento de otras personas ${ }^{56}$. Si la crítica de Celano está en lo cierto, los procedimientos comunes no pueden reemplazar el papel desempeñado por las intenciones comunes en la agencia compartida; por ello, la teoría del derecho como un plan de Shapiro falla al intentar dar una explicación de la normatividad del derecho. Bernal discute la objeción de Celano en su ensayo y llega a la siguiente conclusión: "lo

${ }^{56}$ Celano, B., "What can Plans do for Legal Theory?", en Canale, D. y Tuzet, G. (eds.), The Planning Theory of Law, London, Springer, 2013, pág. 129 y ss. 


\section{Damiano Canale}

que fundamenta a la autoridad jurídica y la normatividad del derecho es el hecho de que los sujetos de derecho consideren 'moralmente legítimo' que las autoridades oficiales creen el plan maestro y que ellos planeen permitir que estas autoridades jurídicas creen los planes que han de regir a toda la sociedad" 57 . La normatividad del derecho podría ser explicada acudiendo al "propósito normativo" del derecho, i. e., el hecho de que el derecho es una forma de organización social que busca compensar los déficits morales de otros tipos de planes tales como la costumbre, la tradición, la persuasión, el consenso y la promesa $^{58}$. Ahora bien, según entiendo, esta respuesta es poco convincente. La teoría del propósito moral de Shapiro da cuenta de una propiedad funcional del derecho: el derecho es un artefacto humano creado con el fin de dar buenas soluciones a problemas morales relevantes, independientemente del hecho de que el derecho sea realmente utilizado para este fin y nos permita lograrlo. Desde el punto de vista jurídico, entonces, si dotamos de autoridad jurídica a un funcionario "no estamos necesariamente imputándole autoridad moral"59. Quien se encuentra sometido al derecho puede estar jurídicamente obligado a realizar ciertas acciones sin estar verdaderamente obligado a realizar esa acción"60.

${ }^{57}$ Bernal Pulido, C., op. cit., pág. 67.

58 "Cuando una comunidad se enfrenta a problemas morales que son numerosos y serios, y cuyas soluciones son complejas, contenciosas o arbitrarias, ciertos modos de planeación como la improvisación, la auto-organización, la negociación privada, el consenso común, o las jerarquías personalizadas serán difíciles de desarrollar, a veces prohibitivas. A menos que la comunidad tenga una mantera de reducir los costos de los riesgos de la planeación, resolver estos problemas morales será, en el mejor de los casos, caro y, en el peor, imposible. En la Teoría del Derecho como un Plan, el objetivo fundamental del derecho es tratar las demandas morales de un modo eficiente". Shapiro, S., op. cit., pág. 213.

${ }^{59}$ Ibíd., pág. 185.

${ }^{60}$ Shapiro remarca que las pretensiones de la autoridad jurídica admiten dos interpretaciones diferentes. Según una interpretación adjetival de estas pretensiones, "la autoridad jurídica implica una autoridad moral": quien posee autoridad jurídica tiene también autoridad moral por el hecho de ser un funcionario en una institución jurídica. Como consecuencia, los planes 
¿El derecho está fundado en la acción colectiva?

Diciendo que estamos jurídicamente obligados a $\phi$ simplemente decimos que las reglas autorizadas de un sistema jurídico son moralmente legítimas aunque no nos sintamos obligados a $\phi$. Por lo tanto, la tesis del propósito moral no explica cómo los funcionarios pueden hacer planes para otros individuos y ordenar que los cumplan. Pero incluso si uno asume, en aras de la discusión, que los planes sociales masivos son posibles, la teoría del derecho como un plan enfrenta aquí un problema adicional. Shapiro sostiene que los planes disponen a los participantes de una práctica social a cumplir porque la racionalidad instrumental se los requiere ${ }^{61}$. Sería irracional adoptar un plan sin asumir el compromiso de llevarlo a cabo. Pero ¿la racionalidad instrumental es realmente normativa? Este es, en verdad, un tema controvertido.

Debo considerar una objeción a la presunta normatividad de la racionalidad instrumental que me parece atractiva en este contexto. Según Shapiro, si una persona planea hacer $\phi$, y cree que hacer $\pi$ es un medio necesario para $\phi$, entonces debe hacer $\pi$ o abandonar su plan de hacer $\phi$. Asumiendo que los planes expresan actitudes tales como intenciones comunes o intenciones individuales, la tesis de Shapiro puede ser reformulada del siguiente modo: si una persona pretende hacer $\phi$ y cree que hacer $\pi$ es el medio necesario para $\phi$, entonces debe

compartidos moralmente ilegítimos no pueden conferir autoridad jurídica a nadie. Pero esta interpretación es criticada por Shapiro porque "cierra la posibilidad de regímenes jurídicos moralmente ilegítimos". Ibíd., p. 185. Así pues, la teoría del derecho como un plan adopta una interpretación perspectival de la pretensión de autoridad jurídica: "la clave aquí es reconocer que, aunque el término 'autoridad' referido a la autoridad jurídica se refiere a un poder moral, la palabra 'jurídica' a menudo no modifica esta frase sustantival; sino que, su rol es cuantificar la afirmación en la que se encuentra integrada. Cuando dotamos de autoridad jurídica a alguien [...] estamos diciendo que, desde el punto de vista jurídico, la persona en cuestión tiene poder moralmente legítimo". Ibíd. En consecuencia, la tesis del propósito moral admite solamente una interpretación perspectival. Decir que el derecho tiene un objetivo moral significa que, desde el punto de vista jurídico, los planes jurídicos son moralmente legítimos; pero no significa que sea (moralmente) obligatorio adoptar dicho plan.

${ }^{61}$ Shapiro, S., op. cit., págs. 123, 142-143, 183. 


\section{Damiano Canale}

hacer $\pi$ o abandonar su intención de $\phi$. En otras palabras, tener la intención de $\phi$, y creer que hacer $\pi$ es un medio necesario para conseguir $\phi$, nos da una razón para $\pi$. Ahora, imagine la siguiente situación: un hombre un poco tonto pretende dejar caer un piano en su cabeza y cree que comprar un piano es el medio necesario para hacerlo. ¿Diríamos que este hombre está racionalmente obligado a comprar un piano? Por supuesto diríamos que no. ¿Por qué? Porque solo tener una intención y una creencia no genera una obligación. John Broome ha propuesto una explicación lógica para esta intuición. Según Broome, el principio de la racionalidad instrumental admite solo una interpretación amplia ${ }^{62}$ : este principio no puede ser traducido a condicionales del tipo "si pretendes $\phi$, entonces debes $\pi$ "; sino que su forma condicional es capturada por un condicional del tipo "debes hacer eso si pretendes $\phi$ entonces $\pi$ "63. Este último condicional tiene un amplio alcance debido a que la normatividad no determina al consecuente, sino a la afirmación condicional entera, tal como se da en la forma lógica $\mathrm{D}(\mathrm{p} \rightarrow \mathrm{q})$. Pero la conclusión "debes $\pi$ " no puede ser inferida de un condicional normativo de amplio alcance por el modus ponens ${ }^{64}$. En otras palabras, esta conclusión no se sigue del principio de la racionalidad instrumental: debe añadirse una premisa normativa mayor que califique el objetivo pretendido como algo que debemos conseguir. Suponiendo que las afirmaciones de deber expresan razones para la acción, si se aspira a $\phi$ no hay ninguna razón para adoptar los medios necesarios para $\phi^{65}$. Por lo tanto, adoptar un plan no es una condición

${ }^{62}$ Ver Broome, J., "Normative Requirements", Ratio, 12, 1999, págs. 398-419.

63 "Si pretendías $\phi$, entonces debías $\pi$ " es una traducción al español de la forma lógica $\rightarrow \mathrm{Dq}$, mientras que "debes hacer eso si pretendes $\phi$ entonces $\pi$ " es una traducción (tentativa) de $\mathrm{D}(\mathrm{p} \rightarrow \mathrm{q})$. Para expresar la última forma lógica en español, uno tiene que forzar la sintaxis para que "deber" tome forma de proposición y no de infinitivo.

${ }^{64}$ Una afirmación normativa de amplio alcance tal como $\mathrm{D}(\mathrm{p} \rightarrow \mathrm{q})$ se satisface siempre que alguna de las condiciones de verdad del condicional material $p \rightarrow q$ se encuentren, lo que es independiente de las causas o razones que hacen $\mathrm{p}$ y q verdaderas o falsas.

${ }^{65}$ Christine Korsgaard ha arribado a una conclusión análoga partiendo de diferentes premisas. Ella ha sugerido que el juicio acerca de si debemos $\pi$, 
¿El derecho está fundado en la acción colectiva?

suficiente para estar obligado a llevarlo a cabo. Los planes no tienen la fuerza normativa del "deber"; sino que establecen requerimientos de coherencia medios-fines que son de ayuda en la evaluación de la agencia humana ${ }^{66}$.

Habiendo dicho todo esto, el problema al que se enfrenta Bernal al respaldar la teoría del derecho como un plan podría ser resumido del siguiente modo. Si la teoría del derecho como un plan tiene asidero, en el sentido de que es capaz de explicar la normatividad del derecho, entonces la tesis de la práctica social se aplica solo respecto de la práctica social que origina el plan maestro de un sistema jurídico. Una vez que el plan maestro ha sido establecido, un sistema jurídico puede continuar existiendo incluso si los funcionarios no actúan conjuntamente sobre la base de intenciones comunes. Por el contrario, si la teoría del derecho como plan se queda corta al explicar

siendo $\pi$ un medio necesario para conseguir $\phi$, depende del contenido de $\phi$. Según Korsgaard, elegir un fin obliga a perseguirlo solo si (a) este fin es valioso y (b) es verdaderamente un fin contingente del agente. Ver Korsgaard, C. (1997). "The Normativity of Instrumental Reason", en Korsgaard, C., The Constitution of Agency. Essays on Practical Reason and Moral Psychology, Oxford, Oxford UP, págs. 26-68.

${ }^{66}$ Joseph Raz y Niko Kolodny han sostenido que la racionalidad instrumental no puede ser descripta como un requerimiento de coherencia medios-fin. Cuando uno pretende $\varphi$ hay un hecho de la cuestión que determina si debemos o no $\varphi$. Por lo tanto, esos casos en los que la coherencia medio-fin falla pueden ser fácilmente explicados como violaciones de un requerimiento normativo que es diferente al requerimiento de coherencia, i. e. por un hecho normativo en lugar del hecho (ficticio) de que hay un compromiso para con la coherencia medios-fin en la agencia humana. Ver Raz, J., "The Myth of Instrumental Rationality", Journal of Ethics and Social Philosophy, 1, 1, 2005; Kolodny, N., "The Myth of Practical Consistence", European Journal of Philosophy, 16, 3, 2008. Como resultado, la racionalidad instrumental sería un "mito": no habría "ninguna forma distinta a la racionalidad [...] que merezca el nombre de racionalidad instrumental" (Raz, J., From normativity to responsibility, Oxford-New York, Oxford University Press, 2011, pág. 165). No discutiré el argumento de Raz aquí. Para contribuir a este artículo, es suficiente decir que Raz y Kolodny presentan un argumento incluso más fuerte que el mío, en contra de la presunta normatividad de la racionalidad instrumental. 
la normatividad del derecho - sea porque no es posible hacer planes por otros, como Bruno Celano ha remarcado, o sea porque la racionalidad instrumental no genera o justifica obligaciones genuinas, como he intentado demostrar previamente-, entonces Bernal no debería avalar la teoría del derecho como un plan de Shapiro como una explicación adecuada de la práctica que fundamenta al derecho.

\section{Conclusión}

En este artículo he intentado mostrar que una lectura crítica de Austin, Hart y Shapiro puede llevar a darnos cuenta de algunas debilidades de la tesis de la práctica social de Carlos Bernal. La tesis de Bernal parece pasar por alto algunos aspectos característicos del derecho, o tratarlos como periféricos de un fenómeno social. (i. e. la acción intencional colectiva) que no parece, a primera vista un "caso central" de la práctica jurídica. En particular, la tesis de la práctica social se queda corta al explicar la existencia de relaciones verticales entre quienes ejercen poderes públicos o privados y quienes están sometidos a dichos poderes ${ }^{67}$. Las relaciones de sujeción frecuentemente caracterizan a las actividades e instituciones jurídicas, incluyendo ambas tanto a ciudadanos como funcionarios, y son establecidas por formas de dominación y control interpersonales, algunas veces acompañadas por el uso de la fuerza, que no pueden ser descriptas como actividades intencionales colectivas ${ }^{68}$. Por supuesto, uno podría sostener —como

${ }^{67}$ Uso el término "poder" y la expresión "ejercicio del poder" en un sentido general. Siguiendo a Searle, podríamos decir que "el poder es ejercido cuando el agente hace que el sujeto quiera algo que él o ella no hubiese querido de otro modo, o cuando limite la percepción del sujeto respecto de las opciones disponibles", i. e. restringe el rango de las elecciones aparentes disponibles para el sujeto sobre el cual se ejerce el poder. Ver Searle, J. R., Making the Social World. The Structure of Human Civilization, Oxford-New York, Oxford University Press, 2010, pág. 160.

${ }^{68}$ Las explicaciones filosóficas de la agencia compartida generalmente asumen que hay libertad interna con respecto a la coerción física y psicológica dentro de un grupo social. Además, los grupos normalmente se encuentran libres de la coerción exterior en su toma de decisiones y aceptación del 
¿El derecho está fundado en la acción colectiva?

Hart, Shapiro y muchos otros hacen - que las relaciones de sujeción no son condición necesaria para la existencia de organizaciones jurídicas y que por ello no vale la pena que la teoría del derecho las considere. Incluso cuando la primera idea fuera cierta, me parece que tanto la teoría del derecho como la ontología social se deberían preguntar si las relaciones de sujeción generadas por el ejercicio del poder pueden ser una condición suficiente para establecer un sistema jurídico y/o mantener un gobierno legítimo.

Una investigación de este tipo podría alumbrar un gran número de fenómenos que habitan la realidad social y jurídica pero que son considerados por la teoría del derecho contemporánea como asuntos pertenecientes al dominio de la filosofía moral y política: el hecho de que las normas jurídicas y las instituciones sean a veces sistemáticamente utilizadas para aterrorizar a los destinatarios del derecho, para crear y mantener un estado de angustia en un grupo, para dañar a las personas, para dar lugar a una "encerrona" [entrapment] personal o para manipular las creencias, deseos e intenciones de las personas de varias maneras ${ }^{69}$. Desde el punto de vista jurídico, ¿por qué ocurren

grupo. Ver Toumela, R., The Philosophy of Sociality. The Shared Point of View, Oxford, Oxford UP, 2007, pág. 15. Desde mi punto de vista, estas suposiciones hacen que el análisis filosófico estándar de la agencia compartida se vuelva poco útil para entender un gran número de actividades jurídicas.

${ }^{69}$ Cf. Raz, J., From normativity to responsibility, op. cit., pág. 221-222. Al criticar la tesis de Fuller sobre la moralidad interna del derecho - según la cual los regímenes jurídicos deberían necesariamente satisfacer un conjunto de requerimientos morales tales como la generalidad, la claridad, la prosperidad, etc.- Raz sostiene, y desde mi punto de vista correctamente, que "el derecho crea inevitablemente un gran peligro de poder arbitrario [...]. De igual modo, el derecho puede ser inestable, oscuro, retrospectivo, etc. y así infringir la libertad y la dignidad del hombre [...]. El derecho no es un simple hecho más de la vida. [...] Es una herramienta al alcance de los hombres, que a diferencia de muchas otras es versátil y capaz de ser usada para una larga variedad de propósitos adecuados". Ibíd., págs. 224 y 226. Lo que quiero recalcar aquí es que la ontología social debería clarificar qué características del derecho hacen posible usarlo como un instrumento de dominación y opresión y en qué medida estas características son parte de la naturaleza del derecho. 


\section{Damiano Canale}

fenómenos de este tipo? De hecho, la tesis de la práctica social tiende a dibujar un velo sobre estas (posibles) funciones del derecho y a concebir las prácticas jurídicas que involucran a los ciudadanos o los funcionarios como actividades conciliadoras y cooperativas que no abarcan desacuerdos ni conflictos sociales.

Además, la teoría de la práctica social no tiene en cuenta ciertas características distintivas de las instituciones jurídicas: por ejemplo, el hecho de que las actitudes de los ciudadanos puedan ser irrelevantes en lo que respecta a la existencia de un sistema jurídico, o que un sistema jurídico pueda existir incluso si los funcionarios están completamente alienados y no persiguen intencionalmente ningún objetivo común ${ }^{70}$. Un acercamiento socio-ontológico a las instituciones jurídicas debe explicar por qué todo esto es posible.

Al mismo tiempo, he tratado de demostrar en este artículo que el problema de la normatividad del derecho, que se encuentra en el centro de la investigación de Bernal, permite diferentes soluciones dependiendo de la manera en la cual el problema sea encarado. Como David Enoch ha manifestado, "no está para nada claro qué se supone que sea el problema de la normatividad del derecho. De hecho, no hay un solo problema aquí, dado que la gente parece tener en mente diferentes problemas cuando usan esta inútil frase"71. En Austin, el problema de la normatividad es un problema empírico relacionado con la cantidad de consentimiento que es necesario para la existencia de una autoridad política; en Hart el problema de la normatividad es un problema tanto empírico como conceptual: atañe a los hechos sociales que un observador tiene en cuenta cuando atribuye disposiciones y

${ }^{70}$ Leslie Green hizo una afirmación fuerte con respecto a la relación entre los regímenes jurídicos institucionalizados y la alienación: "la naturaleza del derecho como un sistema institucionalizado de normas hace endémicamente posible alienarse de este modo". Green, L., "Positivism and the Inseparability of Law and Morals", New York University Law Review, 83, 2008, pág. 1057. Para una discusión crítica de esta visión, ver Wilkinson, M. A., "Is Law Morally Risky? Alienation, Acceptance and Hart's Concept of Law", Oxford Journal of Legal Studies, 30, 3, 2010, págs. 441-466

${ }^{71}$ Enoch, D., "Reason-Giving and the Law", en Green, L. y Leiter, B. (eds.), Oxford Studies in Philosophy of Law: Volume 1, Oxford, Oxford UP, 2011. 
actitudes a agentes calificados; según Shapiro, además, el problema de la normatividad atañe a la estructura de la agencia social masiva y a las condiciones racionales de su coordinación y control; finalmente, en la teoría de Bernal, el problema de la normatividad apunta a clarificar qué acciones y actitudes de los hombres hacen que las entidades sociales, tales como las normas y las instituciones jurídicas, sean posibles. Ahora bien, en lo personal considero que distinguir distintas formulaciones del problema de la normatividad es una condición necesaria para clarificar qué tipo de indagación se necesita para encaminarla. De hecho, uno podría afirmar que la forma en que el problema de la normatividad se encuentra planteado afecta enormemente la tarea de la teoría del derecho y sus métodos de investigación: especificar en qué consiste tal problema requiere tomar cartas en un asunto más general, i. e. el propósito de la teoría del derecho. La ontología social debería ser consciente de esto y especificar qué contribución puede ofrecer a cada tipo de indagación filosófica.

\section{Bibliografía}

Austin, John, The Province of Jurisprudence Determined. Rumble, W. E. (ed), Cambridge, Cambridge UP, 1995.

Baker G. P. y Hacker, P. M. S., Wittgenstein: Rules, Grammar and Necessity, London, Blackwell, 2009.

Bernal Pulido, C., "Austin, Hart, y Shapiro. Tres variaciones alrededor del derecho como una entidad fundada en una práctica social", Discusiones, XIV, 2014, págs. 21-72

Bratman, M., Faces of Intention, Cambridge, Cambridge UP, 1999.

Broome, J., "Normative Requirements", Ratio, 12, 1999, págs. 398-419.

Canale, D., "Consequences of Pragmatic Conceptualism. On the Methodology Problem in Jurisprudence", Ratio Juris, 22, 2009, págs. 171-186.

Canale, D., "Looking for the Nature of Law: On Shapiro's Challenge", Law and Philosophy, 31, 2012, págs. 409-441. 
Celano, B., "What can Plans do for Legal Theory?", en Canale, D. y Tuzet, G. (eds.), The Planning Theory of Law, London, Springer, 2013.

Coleman, J. L., The Practice of Principle. In Defence of a Pragmatist Approach to Legal Theory, Oxford, Oxford University Press, 2001.

Dworkin, R., Law's Empire, Cambridge-London, Belknap Press of Harvard University Press, 1986.

Enoch, D., "Reason-Giving and the Law", en Green, L. y Leiter, B. (eds.), Oxford Studies in Philosophy of Law: Volume 1, Oxford, Oxford UP, 2011, págs. 1-38.

Green, L., "Positivism and the Inseparability of Law and Morals", New York University Law Review, 83, 2008.

Hart, H. L. A., The Concept of Law, Oxford, Clarendon Press, 1994 [1961].

Kolodny, N., "The Myth of Practical Consistence", European Journal of Philosophy, 16, 3, 2008, págs. 366-402.

Korsgaard, C., The Constitution of Agency. Essays on Practical Reason and Moral Psychology, Oxford, Oxford UP, 1997.

Marmor, A., Philosophy of Law. Princeton, Princeton University Press, 2011.

Putnam, H., "The Meaning of Meaning", en Putnam, H. (ed.), Mind, Language and Reality, Cambridge, Cambridge University Press, 1975.

Raz, J., The Authority of Law. Essays on Law and Morality, Oxford, Clarendon Press, 1979.

Raz, J., Practical Reason and Norms, Oxford, Oxford University Press, 1990 [1975].

Raz, J., "The Myth of Instrumental Rationality", Journal of Ethics and Social Philosophy, 1, 1, (2005), págs. 1-28.

Raz, J., From normativity to responsibility, Oxford-New York, Oxford University Press, 2011.

Schauer, F., "Was Austin Right After All? On the Role of Sanctions in a Theory of Law", Ratio Juris, 23, 2010, págs. 1-21.

Searle, J. R., Making the Social World. The Structure of Human Civilization, Oxford-New York, Oxford University Press, 2010. 
Shapiro, S., Legality, Cambridge, Harvard University Press, 2011.

Toh, K. (2010). "The Predication Thesis and a New Problem about Persistent Fundamental Legal Controversies", Utilitas, 22.

Toumela, R., The Philosophy of Sociality. The Shared Point of View, Oxford, Oxford UP, 2007.

Warnock, G. J., The Object of Morality, London, Methuen, 1971.

Weber, M., Economy and Society. An Outline of Interpretive Sociology, Barkely-Los Angeles-London, G. Roth and C. Wittich, 1978.

Wilkinson, M. A., "Is Law Morally Risky? Alienation, Acceptance and Hart's Concept of Law". Oxford Journal of Legal Studies, 30, 3, 2010, págs. 441-466. 